\title{
Results of Endoscopic Treatment of Benign Prostatic Hyperplasia in Patients with Metabolic Syndrome
}

\author{
Rakhmonov O. M. \\ Urologist, Urologic Complex Clinic, Uzbekistan \\ Corresponding author email: oybekrakhmonov@gmail.com \\ Shadmanov A. K. \\ Doctor of Medical Sciences, Professor, Rector, Tashkent Medical Academy, Uzbekistan \\ Juraev F. M. \\ Oncologist, Urologic Complex Clinic, Uzbekistan
}

\begin{abstract}
The present paper is about the research conducted on the patients with metabolic syndrome and its results of endoscopic treatment of benign prostatic hyperplasia in these patients. It is generally accepted that the size and volume of the prostate gland is the main prognostic factor affecting the intraoperative and postoperative outcomes of endoscopic treatment of BPH. However, with the rapid development of endoscopic instruments and surgical techniques, the size of the prostate tends to have a lesser influence on the outcome of endoscopic BPH treatment. Currently, MS is becoming an increasingly common disease, which in most cases predicts a poor prognosis for treatment of patients with LUTS.
\end{abstract}

Keywords---holmium enucleation, intraoperative blood loss, metabolic syndrome, prostatic hyperplasia, transurethral resection

\section{Introduction}

Benign prostatic hyperplasia (BPH) is one of the most common diseases in men. Thus, BPH is observed in $88 \%$ of men over 80 years of age (Unnikrishnan et al., 2017). In most cases, this disease manifests itself and is complicated by symptoms of the lower urinary tract (SLUT), urinary tract infections, hematuria and acute urinary retention (Sebastianelli \& Gacci, 2018). Analysis of literature data showed that in patients with BPH with acute urinary retention, mortality within one year increases with age from 5.3\% in patients aged 55-64 years to $17.9 \%$ in patients aged 75-84 years (Armitage et al., 2007). Although the cause of BPH is still unclear, aging and androgen metabolism are the main pathogenetic factors of BPH, and studies have also shown that family history, smoking, diabetes, hyperinsulinemia, hypertension and obesity are also risk factors for the development of the disease (Xu et al., 2016; Calogero et al., 2019).

\section{The Main Findings and Results}

Metabolic syndrome (MS) is a group of complex metabolic disorders, including abdominal obesity, high blood pressure, hyperglycemia, hyperinsulinemia, and dyslipidemia (Lombard et al., 2002). Because of the unhealthy lifestyle of people, the prevalence of MS is growing worldwide, affecting about $25 \%$ of the world's adult population (Chew et al., 2006). Currently, scientists note that MS and / or its components may be associated with BPH (De Nunzio et al., 2018). The debate about the effect of MS on BPH is still relevant today, although in 2015 MauroGacci and co-author conducted a very thorough and detailed meta-analysis on the issue. The results of this meta-analysis showed that the major factors of MS, in particular dyslipidemia and central obesity, are specifically associated with 
prostate enlargement. Given that MS essentially develops in the presence of certain risk factors, the authors concluded that the same risk factors that lead to MS also play a primary role in the onset of BPH (Gupta \& Gupta, 2010). Considering the above, an integrated approach to the treatment of BPH in patients with MS is strongly recommended (Gacci et al., 2015). To date, the world literature is daily replenished with a huge scientific and practical base, proving the important role of systemic hormonal and metabolic disorders (age-related androgen deficiency, metabolic syndrome, obesity, insulin resistance, dyslipidemia, endothelial dysfunction, oxidative stress, etc.), and leading to BPH as a systemic disease. Considering the growing evidence of the influence of MS on the processes of the course and formation of $\mathrm{BPH}$, the purpose of our study was to study the effect of MS on the results of surgical treatment of BPH (Lodde et al., 2003; Anson et al., 1995).

\section{Materials and Methods}

The study included 180 patients who were examined and treated at the Urologiccomplex clinic from 01 August 2016 to 01 August 2020. All patients underwent endoscopic surgical treatment including bipolar transurethral resection of the prostate (TURP) or holmium laser enucleation of the prostate (HoLEP). The diagnosis in all cases would be verified by subsequent histological examination of the removed prostate tissue, in several cases adenocarcinoma of the prostate gland was histologically verified, these patients were not included in the study (Sulaeman et al., 2018; Laraeni et al., 2021). The examination plan for all groups of patients was the same; the examination of patients was carried out at the prehospital stage, on an outpatient basis at the UrologicComplex clinic. During the initial treatment with complaints of difficulty or impaired urination, all patients underwent a thorough history taking with specification of the duration of complaints, collection of anthropometric data, the amount and type of drug treatment, the duration of drug treatment and the effectiveness of drug treatment prior to surgery. In addition, to unify subjective sensations, obtain subjective information about the severity of lower urinary tract symptoms and their impact on quality of life, and to analyze the duration and severity of prostate symptoms, according to international standards, "International Scale for the Assessment of Prostate Symptoms" (IPSS) was used. The complex of instrumental research methods for all patients of the groups was also the same and included the following research methods: ultrasound of the prostate gland, TRUS, uroflowmetry, ECG, EchoCG. All 180 patients in the preoperative period underwent complex diagnostics, which included (Carson III \& Rittmaster, 2003; Wilson, 1980).

Depending on the presence of metabolic syndrome, the patients were divided into 2 groups. Of the 180 patients included in the study, $97(58.3 \%)$ patients were included in group 1, in this group of patient metabolic syndrome was diagnosed according to WHO recommendations in 2004. Group 2 included $83(46.2 \%)$ patients who did not there were signs of MS. According to the type of surgical treatment, patients in group 1 with metabolic syndrome underwent: TURP - $59(60.8 \%)$ patients, HoLEP - $38(39.2 \%)$ patients. In group 2, patients without metabolic syndrome underwent: TURP - 46 (55.4\%) patients, HoLEP - 37 (44.6\%) patients. To assess the effect of metabolic syndrome on the immediate results of endoscopic treatment of patients with DNPZH, patients underwent a study of intraoperative blood loss and the duration of the operation (Sivaprakasapillai et al., 2009; Moon et al., 2004).

\section{Results}

The age of the patients included in the study ranged from 50-83 years; the average age of the patients was 66 years. The IPSS in group 1 was 26.6 points and 22.8 points in the group of patients without metabolic syndrome. The body mass index in the 1st group of patients was 35.8 in the group of patients without metabolic syndrome - 26.4. The volume of the prostate gland in both groups was practically identical and amounted to $59.6 \mathrm{ml} 3$ and $58.2 \mathrm{ml} 3$, respectively, in the groups. Qmax in the group of patients with metabolic syndrome was $8.2 \mathrm{ml}$, while this figure was $12.4 \mathrm{ml}$ in the group of patients without metabolic syndrome. The residual volume in the group of patients with metabolic syndrome was $142 \mathrm{ml}$, in the group of patients without metabolic syndrome - $94 \mathrm{ml}$. The PSA level, contrary to our expectations, did not statistically significantly differ in both compared groups and amounted to almost identical values of $3.73 \mathrm{ng} / \mathrm{ml}$ in patients with MS and $3.46 \mathrm{ng} / \mathrm{ml}$ in patients without MS. 
Table 1

Clinical characteristics of patients included in the study

\begin{tabular}{lccc}
\hline \multicolumn{1}{c}{ Indicator } & $\begin{array}{c}\text { Group I of patients with } \\
\text { metabolic syndrome } \mathrm{n}=97\end{array}$ & $\begin{array}{c}\text { Group II of patients without } \\
\text { metabolic syndrome } \mathrm{n}=83\end{array}$ & $\mathrm{P}$ value \\
\hline Average age & 65,51 & 66,81 & $\mathrm{p}>0,05$ \\
IPSS & 26.6 & 22.8 & $\mathrm{p} \leq 0,001$ \\
Body mass index & 35,8 & 26,4 & $\mathrm{p} \leq 0,001$ \\
Prostate volume & 59,6 & 58,2 & $\mathrm{p}>0,05$ \\
Q-max & $8,2 \mathrm{ml}$ & $12,4 \mathrm{ml}$ & $\mathrm{p} \leq 0,001$ \\
Residual urine volume & $142 \mathrm{ml}$ & $94 \mathrm{ml}$ & $\mathrm{p} \leq 0,001$ \\
PSA level & & 3,46 & $\mathrm{p}>0,05$ \\
\hline
\end{tabular}

When studying the effect of metabolic syndrome on immediate results, data analysis showed that the duration of surgery in patients with metabolic syndrome during transurethral resection of the prostate gland was 119 minutes and during holmium enucleation of the prostate gland was 140 minutes (Farnham et al., 2006; Shir et al., 1995). In the group of patients without metabolic syndrome, transurethral resection of the prostate took 87 minutes on average, and holmium enucleation took 112 minutes. The average blood loss during surgery in patients with metabolic syndrome during TUR was $185.0 \mathrm{ml}$, during holmium enucleation in this group; the average blood loss was $125 \mathrm{ml}$. In the group without metabolic syndrome, these parameters were $130 \mathrm{ml}$ during TUR and $95 \mathrm{ml}$ during holmium enucleation.

Table 2

Immediate results of endoscopic treatment of BPH depending on the presence of metabolic syndrome

\begin{tabular}{|c|c|c|c|c|c|}
\hline & \multicolumn{2}{|c|}{$\begin{array}{c}\text { Group I of patients with } \\
\text { metabolic syndrome } n=97\end{array}$} & \multicolumn{2}{|c|}{$\begin{array}{l}\text { Group II of patients without } \\
\text { metabolic syndrome } n=83\end{array}$} & \multirow[t]{2}{*}{$\mathrm{P}$} \\
\hline & HolEP & TURP & HolEP & TURP & \\
\hline Duration of surgery & $140 \pm 6,3 \mathrm{~min}$ & $112 \pm 6,2 \mathrm{~min}$ & $119 \pm 5,5 \mathrm{~min}$ & $87 \pm 8,0 \mathrm{~min}$ & $(p \leq 0,001)$. \\
\hline $\begin{array}{l}\text { Intraoperative blood } \\
\text { loss }\end{array}$ & 125 мл & 185 мл & 95 мл & 130 мл & $(p \leq 0,001)$. \\
\hline
\end{tabular}

\section{Discussion}

This study showed that MS may adversely affect endoscopic treatment of BPH, despite having nearly identical prostate volume; MS patients had much worse IPSS scores, the most common symptoms being urinary interruption, nocturia, and general obstructive symptoms. A UK study by Kupelian et al. (2009), showed that the presence of MS worsened BPH symptoms, including urinary interruption, decreased urinary pressure, and obstructive symptoms. The results of our study showed that PSA levels did not differ significantly between patients with MS and patients without MS. However, a study in South Korea found that there was a negative and significant correlation between the presence of MS and PSA levels in a man without BPH. Similar results were obtained by Chong Jeong et al. (2010) and Parehomidr (Parekh et al., 2008). All of these studies were conducted in healthy and young middle-aged men. Since PSA levels are strongly correlated with baseline testosterone levels, any comments on the relationship between MS and PSA are confounding factors, and adjustments for age and testosterone levels are needed in future studies (Gilling et al., 2008; Elzayat \& Elhilali, 2007).

\section{Conclusion}

It is generally accepted that the size and volume of the prostate gland is the main prognostic factor affecting the intraoperative and postoperative outcomes of endoscopic treatment of BPH. However, with the rapid development of endoscopic instruments and surgical techniques, the size of the prostate tends to have a lesser influence on the outcome of endoscopic BPH treatment. Currently, MS is becoming an increasingly common disease, which in most cases predicts a poor prognosis for treatment of patients with LUTS. Using BPH as an example, we can see that MS is accompanied by more severe symptoms of LUTS; patients who had MS more often complained of severe symptoms than those who were not obese IPSS $26.6 \pm 2.2$ versus $22.8 \pm 1.0$ despite the fact that the size of the prostate gland was almost the same in both groups. Blood loss during surgery in patients with metabolic syndrome 
was significantly higher than in patients without MS, $155 \pm 10 \mathrm{ml}$ versus $105.0 \pm 3.1 \mathrm{ml}$, regardless of the type of surgery. The average duration of surgery in patients with MS for TURP was $119 \pm 5.5 \mathrm{~min}$, without MS $87 \pm 8.0$ min, for groups of patients who underwent HolEP, the same indicator was $140 \pm 6.3 \mathrm{~min}$ (for patients with MS) and $112 \pm 6.2$ (for patients without MS), respectively. Based on the foregoing, we can conclude that at present not only the size of the prostate gland affects the results of treatment, but also MS is increasingly playing a leading role in the results of endoscopic treatment of BPH.

\section{References}

Anson, K., Nawrocki, J., Buckley, J., Fowler, C., Kirby, R., Lawrence, W., ... \& Watson, G. (1995). A multicenter, randomized, prospective study of endoscopic laser ablation versus transurethral resection of the prostate. Urology, 46(3), 305-310. https://doi.org/10.1016/S0090-4295(99)80211-8

Armitage, J. N., Sibanda, N., Cathcart, P. J., Emberton, M., \& van der Meulen, J. H. (2007). Mortality in men admitted to hospital with acute urinary retention: database analysis. Bmj, 335(7631), 1199-1202.

Calogero, A. E., Burgio, G., Condorelli, R. A., Cannarella, R., \& La Vignera, S. (2019). Epidemiology and risk factors of lower urinary tract symptoms/benign prostatic hyperplasia and erectile dysfunction. The Aging Male, 22(1), 12-19.

Carson III, C., \& Rittmaster, R. (2003). The role of dihydrotestosterone in benign prostatic hyperplasia. Urology, 61(4), 2-7. https://doi.org/10.1016/S0090-4295(03)00045-1

Chew, G. T., Gan, S. K., \& Watts, G. F. (2006). Revisiting the metabolic syndrome. Medical journal of Australia, 185(8), 445-449.

De Nunzio, C., Brassetti, A., Proietti, F., Deroma, M., Esperto, F., \& Tubaro, A. (2018). Metabolic syndrome and smoking are associated with an increased risk of nocturia in male patients with benign prostatic enlargement. Prostate cancer and prostatic diseases, 21(2), 287-292.

Elzayat, E. A., \& Elhilali, M. M. (2007). Holmium laser enucleation of the prostate (HoLEP): long-term results, reoperation rate, and possible impact of the learning curve. european urology, 52(5), 1465-1472. https://doi.org/10.1016/j.eururo.2007.04.074

Farnham, S. B., Webster, T. M., Herrell, S. D., \& Smith Jr, J. A. (2006). Intraoperative blood loss and transfusion requirements for robotic-assisted radical prostatectomy versus radical retropubic prostatectomy. Urology, 67(2), 360-363. https://doi.org/10.1016/j.urology.2005.08.029

Gacci, M., Corona, G., Vignozzi, L., Salvi, M., Serni, S., De Nunzio, C., ... \& Maggi, M. (2015). Metabolic syndrome and benign prostatic enlargement: a systematic review and meta-analysis. BJU international, 115(1), 24-31.

Gilling, P. J., Aho, T. F., Frampton, C. M., King, C. J., \& Fraundorfer, M. R. (2008). Holmium laser enucleation of the prostate: results at 6 years. European urology, 53(4), 744-749. https://doi.org/10.1016/j.eururo.2007.04.052

Gupta, A., \& Gupta, V. (2010). Metabolic syndrome: what are the risks for humans?. Bioscience trends, 4(5).

Jeong, I. G., Hwang, S. S., Kim, H. K., Ahn, H., \& Kim, C. S. (2010). The association of metabolic syndrome and its components with serum prostate-specific antigen levels in a Korean-screened population. Cancer Epidemiology and Prevention Biomarkers, 19(2), 371-380.

Kupelian, V., McVary, K. T., Kaplan, S. A., Hall, S. A., Link, C. L., Aiyer, L. P., ... \& McKinlay, J. B. (2009). Association of lower urinary tract symptoms and the metabolic syndrome: results from the Boston Area Community Health Survey. The Journal of urology, 182(2), 616-625.

Laraeni, Y., Danuyanti, I. G. A. N., Resnhaleksmana, E., Pauzi, I., Mataram, I. K. A., \& Agustini, N. P. (2021). High antioxidant level in cajanus sajan reduces blood glucose level and improves blood lipid profile of rats as diabetes mellitus models. International Journal of Health Sciences, 5(1), 29-37. https://doi.org/10.29332/ijhs.v5n1.725

Lodde, M., Lusuardi, L., Palermo, S., Signorello, D., Maier, K., Hohenfellner, R., \& Pycha, A. (2003). En bloc transurethral resection of bladder tumors: use and limits. Urology, 62(6), 1089-1091. https://doi.org/10.1016/S0090-4295(03)00761-1

Lombard, L., Augustyn, M. N., \& Ascott-Evans, B. H. (2002). The metabolic syndrome pathogenesis, clinical features and management. Cardiovascular Journal of South Africa, 13(4), 181-186.

Moon, Y. S., Kim, D. H., \& Song, D. K. (2004). Serum tumor necrosis factor- $\alpha$ levels and components of the metabolic syndrome in obese adolescents. Metabolism, 53(7), $\quad$ 863-867. https://doi.org/10.1016/j.metabol.2004.02.007

Parekh, N., Lin, Y., Marcella, S., Kant, A. K., \& Lu-Yao, G. (2008). Associations of lifestyle and physiologic factors with prostate-specific antigen concentrations: evidence from the National Health and Nutrition Examination Survey (2001-2004). Cancer Epidemiology and Prevention Biomarkers, 17(9), 2467-2472. 
Sebastianelli, A., \& Gacci, M. (2018). Current status of the relationship between metabolic syndrome and lower urinary tract symptoms. European urology focus, 4(1), 25-27.

Shir, Y., Raja, S. N., Frank, S. M., \& Brendler, C. B. (1995). Intraoperative blood loss during radical retropubic prostatectomy: epidural versus general anesthesia. Urology, 45(6), 993-999. https://doi.org/10.1016/S00904295(99)80120-4

Sivaprakasapillai, B., Edirisinghe, I., Randolph, J., Steinberg, F., \& Kappagoda, T. (2009). Effect of grape seed extract on blood pressure in subjects with the metabolic syndrome. Metabolism,58(12), 1743-1746. https://doi.org/10.1016/j.metabol.2009.05.030

Sulaeman, R., Muhasidah, .-., Purnamawati, D., Zulkifli, .-., Jafar, S. R., \& Suiraoka, I. P. (2018). Progressive muscle relaxation using video aids reduces blood pressure of hypertension patients. International Journal of Health Sciences, 2(3), 33-42. https://doi.org/10.29332/ijhs.v2n3.214

Unnikrishnan, R., Almassi, N., \& Fareed, K. (2017). Benign prostatic hyperplasia: Evaluation and medical management in primary care. Cleveland Clinic journal of medicine, 84(1), 53-64.

Wilson, J. D. (1980). The pathogenesis of benign prostatic hyperplasia. The American journal of medicine, 68(5), 745-756. https://doi.org/10.1016/0002-9343(80)90267-3

Xu, H., Fu, S., Chen, Y., Chen, Q., Gu, M., \& Wang, Z. (2016). Smoking habits and benign prostatic hyperplasia: a systematic review and meta-analysis of observational studies. Medicine, 95(32). 